\title{
Marcação de tempo por surdos sinalizadores
}

\author{
Aline Nascimento Crato ${ }^{1}$
}

Crato AN. Marcação de tempo por surdos sinalizadores [dissertação]. São Paulo: Faculdade de Medicina, Universidade de São Paulo; 2010.

Introdução: Pesquisas nacionais enfatizam que os surdos apresentam dificuldade no uso da flexão verbal de tempo na escrita do português. Buscando compreender melhor este processo, o presente estudo teve como objetivos verificar se e como os surdos flexionam os verbos na Língua Portuguesa Escrita e se eles utilizam outros marcadores de tempo nesta língua e na Língua Brasileira de Sinais. Métodos: O estudo foi realizado com 18 sujeitos com perda auditiva neurossensorial profunda bilateral pré-linguística, com idade entre 15 e 23 anos, escolaridade de $3^{\mathrm{a}}$ a $6^{\mathrm{a}}$ série do Ensino Fundamental, matriculados em sala regular de escola pública, usuários da Língua Brasileira de Sinais. Os indivíduos foram avaliados quanto ao conhecimento em Língua Brasileira de Sinais de nove verbos de ação, por meio de cartelas contendo figuras que os representavam e, em seguida, foram orientados a elaborar três frases na Língua Portuguesa Escrita e na Língua Brasileira de Sinais com cada verbo, sendo uma no tempo passado, uma no presente e uma no futuro. Resultados: Apesar de a maioria dos participantes da pesquisa utilizar adequadamente os mar- cadores de tempo nas frases expressas na Língua Brasileira de Sinais, esperava-se melhor desempenho dos sujeitos por ser a sua língua preferencial de comunicação. Nas frases do passado e do futuro predominaram o uso de adjuntos adverbiais para marcar o tempo e no presente predominou o uso de advérbios de tempo. Nas frases escritas houve o predomínio do verbo na forma nominal do infinitivo. Apenas quatro sujeitos fizeram uso de marcadores utilizados na língua de sinais para indicar o tempo nas frases escritas. Os sujeitos apresentaram melhor desempenho no tempo presente na elaboração das frases na Língua Brasileira de Sinais e na Língua Portuguesa Escrita. Houve relação estatisticamente significante entre o uso das flexões verbais no tempo presente e a utilização de outros marcadores de tempo na escrita com o aumento da escolaridade. Conclusão: A maioria dos surdos do estudo utiliza marcadores de tempo nas frases expressas na Língua Brasileira de Sinais e apresenta dificuldade na Língua Portuguesa Escrita. Os resultados sugerem que com o avanço da escolaridade esta dificuldade é diminuída.

Dissertação apresentada à Faculdade de Medicina da Universidade de São Paulo para obtenção do título de Mestre em Ciências, sob orientação da Profa. Dra. Maria Silvia Cárnio.

(1) Laboratório de Investigação Fonoaudiológica em Leitura e Escrita do Departamento de Fisioterapia, Fonoaudiologia e Terapia Ocupacional da Faculdade de Medicina, Universidade de São Paulo - USP - São Paulo (SP), Brasil. Endereço para correspondência: Aline Nascimento Crato. R. Cipotânea, 51, Cidade Universitária, Butantã, São Paulo (SP), Brasil, CEP: 05360-160. E-mail: aline.crato@bol.com.br 